\title{
Exploring the Adoption process of Personal technologies: a Cognitive-affective approach
}

\author{
Debora Bettiga $^{1}$, Lucio Lamberti² \\ ${ }^{12}$ Department of Management, Economics and Industrial Engineering, Politecnico di Milano, \\ Milano, Italy

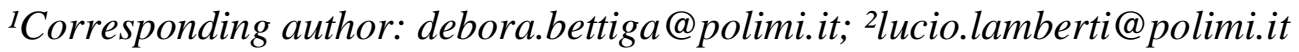

\begin{abstract}
The impact of cognitive and emotional factors on the customer's decision to adopt a new technology has long been at the core of innovation and marketing literature. Today, the proliferation of personal technologies makes the understanding of the adoption process of such innovations a vital issue. This article, moving from long-established technology adoption theories, integrates affective factors to propose a comprehensive framework to interpret and orient innovation and marketing approaches of Companies. To do this, we review a rich literature from the domains of management, information systems, marketing and cognitive psychology, identifying six possible sources of perceived value for personal technologies, hence attitude to adopt them: functional value, monetary value, social value, entertainment value, epistemic value and aesthetic value. After defining and framing them in the extant literature, we discuss how the framework may be adopted in practice to support Companies' strategies in the surprisingly under-explored industry of personal technologies.
\end{abstract}

Keywords: technology adoption; personal technologies; consumer study; innovation; 


\section{Introduction}

The fast-growing digitalization of our societies and the progress in digital technologies have created a blooming business area in the so-called "personal technologies" - that can be defined as "technologies exhibiting a kind of one-to-one binding with the user" (Arbore, Soscia, \& Bagozzi, 2014, p. 90) - such as smartphones, laptops, fitness watches, smart glasses, wearable devices, apps, etc. It is a business area with an unprecedented growth potential. More than 2.500 new apps are published daily and some 20.4 billion connected things interacting with personal technologies are expected to be in use by $2020^{1}$. The potential is as big as competition, and better understanding the possible reasons behind the success of personal technologies represents a fundamental challenge for academicians and practitioners alike.

A major factor for the success of such technologies has been individuated in their ability to offer a permanent connection, permitting new forms of collaboration and interaction (Borges \& Joia, 2015), to provide valuable experiences and to create addictive engagement for the user (Dholakia, 2014). Such hedonistic experience centricity challenges some of the cornerstones of the theories developed, especially during the 1980s and 1990s, to describe the technology adoption process by consumers as the outcome of cognitive processes. As a result, extant literature on technology adoption can catch just a part of the possible impact of affective factors in the user's decision-making (Wolff, Nordin, Brun, \& Berglund, 2011). Marketing and cognitive psychology literature, yet, have broadly studied in time the relevance of affection in consumer behavior: hedonic consumption (Holbrook \& Hirschman, 1982), experiential marketing (Schmitt, 1999a, 1999b) and sensory marketing (Krishna, 2012) are just some of the most significant examples of a consistent body of knowledge

1 Gartner forecast 2017 (http://www.gartner.com/newsroom/id/3598917) 
suggesting that consumers increasingly value, and base their choices on, visceral and emotional dimensions related to the inherent experience the offer provides.

The emergence of personal technologies (Kim \& Shin, 2015) raises the need to lead these two streams of literature back to an unifying point, in which affective and cognitive factors are merged to interpret in a more comprehensive way the technology adoption process, i.e., framing the theories in a broader background, which is natively affective-cognitive. Our paper moves from this assumption and aims at proposing a conceptual framework to encompass the useful, but incomplete, drivers of technology adoption(Schwarz, Chin, Hirschheim, \& Schwarz, 2014), specifically thought in the area of consumption technologies (Haverila, 2013; Thong \& Venkatesh, 2011) and to develop a model of cognitive-affective technology adoption. By doing this, we aim at contributing to extant knowledge in a twofold way: on the one hand, we propose a unifying view of affection and cognition in technology adoption; on the other hand, we develop a conceptual tool to approach further research on the adoption of personal technologies.

Operatively, the paper will first discuss strengths and weaknesses of extant technology adoption theories in order to better frame the affective-cognitive approach in current wisdom. Moving from such theoretical underpinning, we will introduce the conceptual framework and its constituting parts and suggest propositions to be tested empirically. Finally, implications for research and practitioners will be discussed.

\section{Cognitive-affective technology adoption}

\subsection{Cognitive approaches}

Cognitive approaches to technology adoption share the idea that the intention to adopt a technology is the result of a rational processing of different information about the technology and the context of use by the user. Despite several theories have been developed in time, 
three of them have accomplished a universal acceptance and can be considered the reference for this class of approaches: Technology Acceptance Model (TAM; Davis, 1989), Theory of Reasoned Action (TRA; Fishbein \& Ajzen, 1975) and Theory of Planned Behavior (TPB; Ajzen, 1991). These models share the assumptions that (1) human decisions are rational, (2) attitude, as a manifestation of the cognitive processes, is the main determinant of consumer choices, and (3) emotional and affective reactions become relevant only when the cognitive structure is not fully represented (Fishbein \& Middlestadt, 1995). Besides these commonalities, the approaches outline significant differences in the modelling of attitude and its relationship with intentions.

TAM posits that technology adoption is determined by the behavioral intention by the user to adopt such technology; such intention, in turn, is determined by two drivers: perceived usefulness (PU) and perceived ease of use (PEOU), that are the result of the stimuli the user is exposed to ("external variables"). PU and PEOU determine the attitude, which in turn define the behavioral intention, while PU may influence even directly such intention. In time, TAM has undergone several adjustments and refinements that can be summarized in three major streams (King \& He, 2006): (i) study of the antecedents of PU and PEOU, that fully mediate the effect of other constructs. With reference to this stream, image, output quality, subjective norm, job relevance and results demonstrability were identified as the main drivers of PU (Venkatesh \& Davis, 2000), while self-efficacy, anxiety, perception of external control and playfulness as the anchors of PEOU (Venkatesh, Morris, \& Ackerman, 2000). This stream expresses a gradual enclosure of non-merely-rational arguments in technology adoption (e.g., playfulness, anxiety), but interpreted as antecedents of cognitive constructs such as PU and PEOU; (ii) identification of user-level factors (e.g., gender, age or culture) moderating the PU/intention and PEOU/intention relationships (Hu, Hu, \& Al-Gahtani, 2017; Tarhini, Hone, Liu, \& Tarhini, 2017); (iii) enclosure of further factors besides PU and PEOU, 
such as subjective norms (Schepers \& Wetzels, 2007) and, remarkably, hedonic motivations (Slade, Williams, \& Dwivedi, 2015). This line of research tried to answer to the decrease in predictive power of the model over time in specific cases. Its extensive use in different countries, contexts and technologies makes TAM a broadly accepted model to predict technology acceptance (Chuttur, 2009; Roy, Balaji, \& Kesharwani, 2016) for mobile technologies as well (Kitchen, Martin, \& Che-Ha, 2015). Despite this broad consensus, the information processing approach on which it is grounded received several criticisms, especially because it systematically ignores emotional and experiential influences in technology adoption (Schwarz, 1997; Zanna \& Rempel, 1988). The major concern raised regards the assumption that consumer evaluative responses are based primarily on utilitarian beliefs, forgetting affective experience (Zanna \& Rempel, 1988).

TRA and TPB, on the base of which TAM has been developed, share the idea that behaviours are driven by intentions and intentions are driven by attitudes, but include the idea that a social pressure ("subjective norms") may influence the behavioural intention. TPB refines TRA, which does not address incomplete volitional control, by introducing a third antecedent to behavioural intention, i.e. perceived behavioural control, that assesses the extent the user has the required opportunities and resources to perform a behaviour. The conceptual closeness of TAM, TPB and TRA is such that models aimed at encompassing the three of them have been proposed in time, even if they have been less adopted than the individual theories. The most successful is UTAUT (Venkatesh, Morris, Davis, \& Davis, 2003), a model to describe the user intention to use a digital technology based on four key constructs: performance expectancy, effort expectancy, social influence, and facilitating conditions. The model also posits that some individual-related factors such as gender, age, experience and voluntariness of use moderate the impact of the four key constructs on usage intention and behaviours. 
The idea by these models to lead back all the antecedents of the intention and behaviours to issues such as attitudes, beliefs, norms and "technical" variables has a main strength and a main weakness. The main strength lies in the fact that leading back all the model to cognitive, rational variables or cognitive expressions of affective variables, the theories are well suited to be analysed through self-reported measures by the users, increasing the ease of measurement of their actual predictive power. The main weakness they have shown over time is that they appear better predictor of self-reported intentions than of actual behaviours (Armitage \& Conner, 2001). Further, attitude has repeatedly shown to not fully mediate the influence of beliefs on intention (Kim, Lee, Mun, \& Johnson, 2017). This can be attributed to a structural problem of self-reported measures not specifically related to the models, but it clearly shows that cognitive theories are just a partial representation of the technology adoption process, which requires a thorough examination of possible complementary views to improve the overall understanding of the technology adoption phenomena. In particular, literature has largely criticized TPB and other cognitive models for a limited consideration of affective/emotional variables (Rapaport \& Orbell, 2000; Wolff et al., 2011) and this suggests to analyse affective approaches and look for complementarity. While the cognitive antecedents of technology adoption have been well covered, the role of emotions in the process is still understated (George, Ekinci, Simkin, \& Sutan, 2016).

\subsection{Affective approaches}

The perspective that consumers make decisions through a pure reasoned evaluation based on utilitarian beliefs has been challenged starting from the early 80s. As Holbrook \& Hirschman (1982, p. 92) assert, hedonic consumption consists of "those facets of consumer behaviour that relate to the multisensory, fantasy, and emotive aspects of one's experience with products". This approach recognizes the importance of several neglected variables, such as the role of emotions, affect, enjoyment, pleasure and consumption's role in decision-making 
and studies behaviours that do not fit with the traditional view of buying as a consequence of a reasoned action (Addis \& Holbrook, 2001; George et al., 2016). Consumers, indeed, engage not only in rational choices but also in emotional ones (Brakus, Schmitt, \& Zarantonello, 2009). Although the importance of hedonic consumption is widely recognized, the concept itself has not been nearly circumscribed (Alba \& Williams, 2013), having the same Holbrook and Hirschman acknowledged that it lacks clearly defined peculiarities. What these studies have in common is the acknowledgement that hedonic consumption comes from a pleasurable experience with a product or an event (Koshkaki \& Solhi, 2016).

Though, what is an experience? An experience encompasses the simple evaluations based on consumer beliefs, integrating also sensations and emotions. It emerges from a user-product interaction where both the user and the product influence the experience itself (Alba \& Williams, 2013; Forlizzi \& Ford, 2000; Schmitt, 1999b). Users bring their values, feelings and cognitive models for interpreting the world (Dong, Chang, Wang, \& Yan, 2017).

Products bring their features, aesthetic characteristics, language, shape and accessibility. The first one is defined as the consumers' responses in experiencing the product, that can be distinguished along instrumental/cognitive versus emotional/affective processes (Kempf \& Smith, 1998; Millar \& Tesser, 1986). The second one can be attributed to the particularly feelings and emotions the product itself generates. Indeed, all product attributes, such as brand name (McClure, Li, Tomlin, \& Cypert, 2004) and price (Plassmann \& O’Doherty, 2008) affect emotions and feelings, above cognition.

\subsection{Matching the perspectives: towards a cognitive-affective approach}

Understanding the technology adoption process requires knowledge of both the cognitive, information-processing view and of the emotional and experiential view of consumption. Above that, it requires an understanding of the subtle, but remarkably relevant, interplay of cognitive and affective processes that elicit consumer desire and intention. Yet, despite 
several researchers attempt to understand how emotions and affect drive acceptance, they often did not challenge the basic core processes of TAM and the multiattribute attitude model on which it is grounded. Emotions and attitudes, the outcome of cognitive and affective processes respectively, have been in some cases confused in Technology Acceptance studies, in others, relations between emotions and other constructs were not clearly defined (Bagozzi, 2007). As prior research highlights, "What is needed are specific theories of the effect of emotions tailored to technology acceptance" (Bagozzi, 2007, p. 249), especially in the consumer contemporary market, where the role of emotions arises as a significant driver of adoption (George et al., 2016; Morgan-Thomas \& Veloutsou, 2013). When accounted, emotional experience has been usually treated as a distinct source of information on which people rely on, a mere determinant of attitude (Schwarz, 1997; Zanna \& Rempel, 1988). Thus, not considering emotional experience as a distinct process itself. This perspective showed to be useful for employees' targeted technologies in the '80, the early focus of TAM, i.e. contexts in which some forms of coercive pressure might exist and the use of technology was pre-eminently professional and task-oriented. However, technological products for the consumer market and personal devices used in a number of workplaces nowadays, are intrinsically different, thus the reasoned utilitarian approach can hardly fit in this new context. For instance, monetary value turns into a relevant factor for consumers that, contrary to employees, have to pay for the technology (Venkatesh, Thong, \& Xu, 2012). Entertainment value, fun and pleasure become salient when observing the final consumers (Venkatesh \& Davis, 2000). Perceived enjoyment has been found in some cases more important than perceived usefulness in creating consumers' favourable attitude (Kim et al., 2017). Despite prior researchers tried to include these constructs in the study of technology acceptance, achieving a high predictive power and thus confirming their relevance, they were 
often not parsimonious (Bagozzi, 2007) and more crucial, they did not challenge the original multiattribute attitudinal perspective, but only built on it.

Thus, we propose a new approach, which blends the two main views: the reasoned, cognitive and evaluative perspective proposed by the information processing approach (Fishbein \& Ajzen, 1975) on which TAM is built upon, and the affective and emotional perspective, on which the hedonic consumption literature is grounded (Holbrook \& Hirschman, 1982). These two approaches, despite have grown apart, are indeed complementary, as both explain one side of the consumer experience and decision-making processes. If TAM focuses on the reasoned side of technology adoption, where utilitarian benefits lead to the formation of attitude, thus a cognitive appraisal, hedonic consumption focuses on the emotional and affective stimuli that lead to the formation of an emotional reaction, thus an affective process. Yet, which is the psychological mechanism through which attitude and emotions affect the intention to adopt a product? We believe that desire, "a state of mind whereby an agent has a personal motivation to perform an action or to achieve a goal” (Perugini \& Bagozzi, 2004, p.71) is the key link. Desire is, indeed, a fundamental state driving consumer behaviors, providing the motivational impetus for engaging in decision making, by integrating a series of emotional and cognitive appraisals of the consumer (Dholakia, 2014).

\section{A cognitive-affective view of technology adoption}

Our cognitive-affective model of technology adoption (Figure 1) describes the interaction between attitudes (the result of cognitive processes) and emotions (the result of affective processes) as the antecedent of desire and in turn, intention to adopt. 
Figure 1. Cognitive-affective model of technology adoption

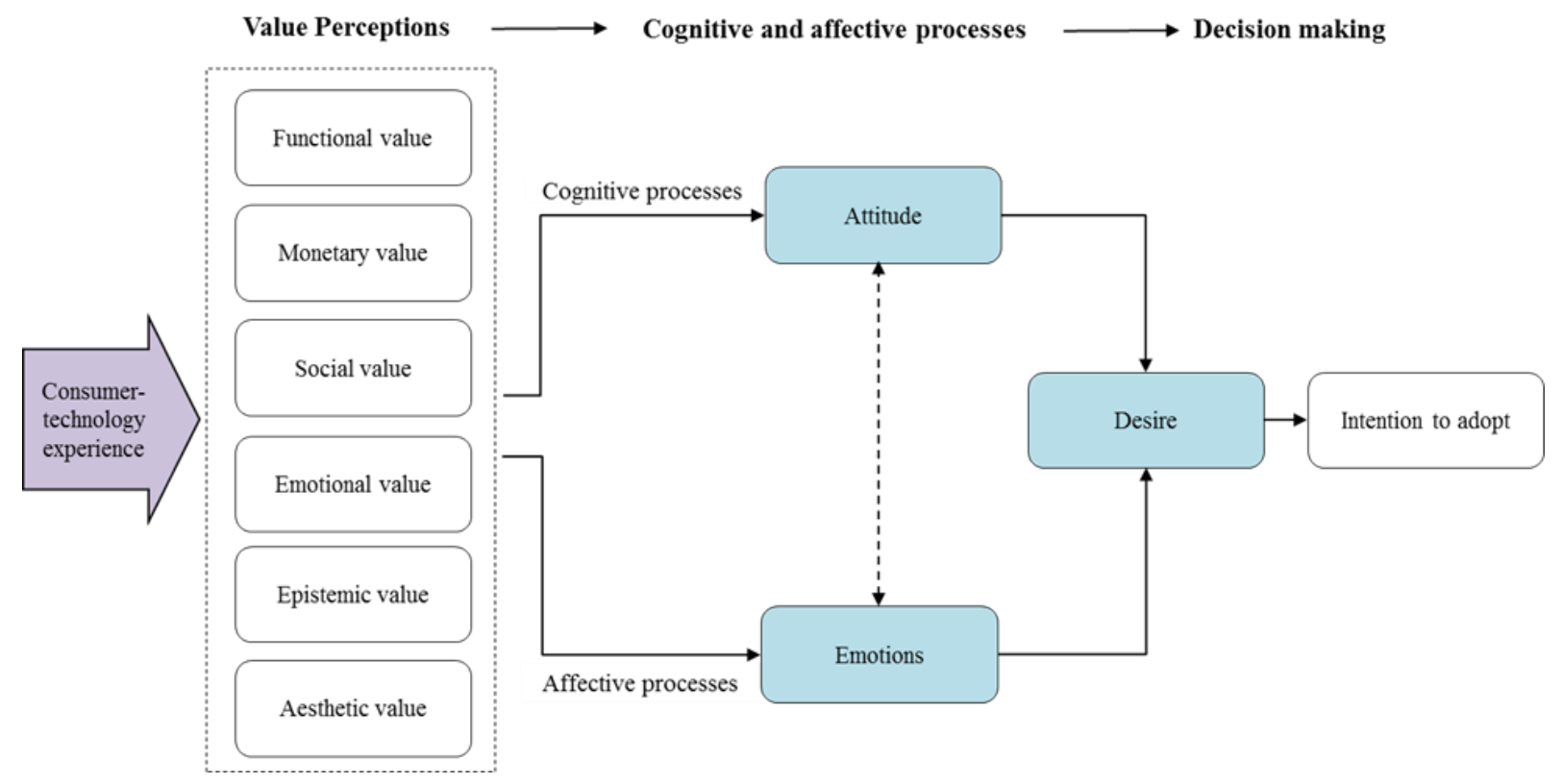

The model suggests a three steps process: (1) according to the multiattribute model, stimuli derived from the consumer-technology interaction lead to the formation of multiple value perceptions in consumer mind. These perceptions are generated by functional and utilitarian information, as TAM suggests, and by hedonic, emotional and social ones, as hedonic consumption research suggests; (2) the value perceptions activate a double concurrent process in the consumer mind: a cognitive process, leading to the formation of attitude, as TAM assumes, and an affective process spurring emotions, proposed by hedonic consumption research (i.e. consumers' responses to the product experience). (3) the cognitive and affective reactions lead to the formation of desire, that is the direct antecedent of intention to adopt a technology. Phase 2 and 3 are universal in nature and can be useful to explain consumption of a wide variety of products, above personal technologies (the "cognitive-affective" and the "decision-making" processes respectively in Fig 2). The drivers of these processes, the value perceptions, are instead specifically tailored to personal technologies. Following, a brief review of the main constructs of the model is presented starting, for clarity reasons, from the value perceptions elicited by the technology, then 
analysing the cognitive and affective processes and finally decision-making outcomes, i.e. desire and intention to adopt.

\subsection{Value perceptions}

Following a review of relevant value perceptions in the product adoption domain (Sheth, Newman, \& Gross, 1991; Sweeney \& Soutar, 2001; Sweeney \& Soutar, 1996; Wan, Wang, Zhang, \& Cao, 2017) and on prior research on Information System, marketing and design fields (Burucuoglu \& Erdogan, 2016; Pura, 2005; Wang, Liao, \& Yang, 2013) six values are proposed as drivers of personal technologies adoption: functional, monetary, entertainment, social, epistemic and aesthetic value. This multidimensional perspective contends that the experience with a product engenders several consumption values (Holbrook, 1996; Holbrook, 1999; Kim, Joo, \& Park, 2017; Ku, Chu, \& Tseng, 2013; Omigie, Zo, \& Rho, 2017; Wang et al., 2013) taking a step further from the bidimensional approach of TAM and the more traditional marketers perspective.

\subsubsection{Functional value}

Functional value represents the value derived from effective task fulfilment and is connected with superiority compared with the alternatives (Sheth et al., 1991). In consumer behaviour literature, efficient task fulfilment has also been referred to the convenience, availability or ease of use. The importance of product functionality in technology adoption has been widely tested and confirmed in various contexts and for different technologies and targets (e.g. Davis, 1989; Venkatesh \& Davis, 2000). Both in TAM and in theories of consumption values (Sheth et al., 1991) functional value is considered to be the primary driver of consumer choice as individuals, when evaluating a new product, usually give a great importance to the technology compatibility with their objectives and its ease of use. Subsequent research has 
confirmed that functional value is a determinant of adoption for a variety of innovations (Bruner \& Kumar, 2005; Venkatesh et al., 2003).

\subsubsection{Monetary value}

Monetary value represents the consumers' cognitive trade-off between the perceived benefits of the technology and the monetary cost for using it (Venkatesh et al., 2012). The focus on the price, above other functional characteristics, has gained relevance with the extension of the original TAM to the consumer setting (Venkatesh et al., 2012), because consumers usually bear the monetary cost of products, whereas employees, the original context of development of TAM, do not. Recent studies on TAM confirmed that monetary value (or price value) is a relevant driver of technology adoption (Overby \& Lee, 2006; Pontiggia \& Virili, 2010; Venkatesh et al., 2012).

\subsubsection{Entertainment value}

Entertainment value is the "perceived utility acquired from an alternative capacity to generate fun or relax in the user" (Sheth et al., 1991, p. 161). It derives from entertainment features, games and fun activities supported by the technological product. For instance, a seamless smartphone interface could make the user feels relaxed and pleased. Enjoyment, entertainment, amusement and hedonism have been confirmed as powerful drivers of adoption for different consumers technologies (e.g. Pai \& Arnott, 2013; Zolkepli \& Kamarulzaman, 2015). The entertainment potential of new high-technological products is expected to have an even stronger influence on the adoption decision.

\subsubsection{Social value}

Social value relates to the social approval and the enhancement of one's self-image among other individuals (Bearden \& Netemeyer, 1999). It is defined as "the perceived utility acquired from an alternative's association with one or more specific social groups" (Sheth et 
al., 1991, p.161). A product or service acquires social value through association with positively or negatively demographic, socio-economic or cultural groups (Sheth et al., 1991). Social value has been identified as a significant driver of technology adoption (Adams, Farrell, Dalgarno, \& Oczkowski, 2017). For new technologies, influencers can play a great role in pushing other consumers' adoption, by acting as early adopters of the innovation themselves and further by disseminating information through word-of-mouth, thus facilitating mass adoption (Lee, Park, \& Im, 2016). As the decision is personal and voluntary, family, friends and the community may have a strong influence on technology decisionmaking process (Kulviwat, Bruner, \& Al-shuridah, 2009). For instance, fitness trackers, such as NIKEiD, have experimented a remarkable success thanks to the possibility of sharing results and fitness goals within a community of sport passionate, in which the user identifies.

\subsubsection{Epistemic value}

Epistemic value is the self-referent value acquired from a technology, which arises curiosity or satisfies a desire of knowledge. Curiosity, novelty seeking and knowledge seeking motivations are assumed at the base of epistemic value (Sheth et al., 1991). Novelty is thought to be an innate human preference (Bianchi, 1998) while curiosity is the desire for knowledge, both arising from a particular stimulus or as a reaction to boredom. Knowledge seeking behaviour reflects, instead, a conscious effort to acquire information for specific purchases (Peterson \& Merino, 2003).

\subsubsection{Aesthetic value}

An aesthetic response is a reaction to the shape, colour, proportion and general pleasantness of a product, that encompasses the merely performance and elicit beauty (Veryzer, 1993). Consumer research confirmed the importance of aesthetics in consumer choice by demonstrating that consumers pursue aesthetics value, above the utilitarian evaluations, also 
within product categories that are not purely aesthetic (Hagtvedt \& Patrick, 2008; Reimann \& Zaichkowsky, 2010). The concept of aesthetic is relevant in personal technologies (Toufani, Stanton, \& Chikweche, 2017), where it translates in both the aesthetic of the product itself (a smartphone or tablet with a distinct colour and design, as Apple success confirms) and the interface of such devices, where colours, clarity and brightness constitute essential elements. Aesthetic value has been proved to affect cognitive responses of consumers that are more willingness to accept and experience satisfaction with aesthetically appealing works but also in affective responses to consumption, where consumers experience excitement and delight (Chitturi, Raghunathan, \& Mahajan, 2008).

The specific outlooks mentioned (Pura, 2005; Sheth et al., 1991; Sweeney \& Soutar, 2001; Sweeney \& Soutar, 1996; Wang et al., 2013) have explored issues related to the multicomponent nature of perception, elicited by both functional features and by hedonic and emotional characteristics of the offer. The multicomponent nature of perceived value in Figure 1 suggests that personal technologies generate a multidimensional experience, touching several consumption values (Holbrook, 1999; Holbrook, 1996). Therefore:

Proposition 1: Consumer-technology experience generates functional, monetary, entertainment, social, epistemic and aesthetic value perceptions.

\subsection{Cognitive and affective processes: attitude and emotions}

Our model proposes that value perceptions are elaborated through both a cognitive and an emotional process. Regarding the cognitive process, no one contests that value perceptions activate cognition, being perceptions the awareness or understanding of sensory information (Krishna, 2012). Perception affects attitude and behaviour, as the information processing perspective assumes (Ajzen, 1991; Fishbein \& Ajzen, 1975) and recent contributions confirmed that even mental imagery or mental simulation may be enough to drive cognitive 
processes (Krishna, 2012). Nevertheless, while it is intuitive that beliefs and values determine attitude, they have been confirmed to elicit emotional responses as well. Consumption emotions refer to this set of emotional responses activated during product experiences, as described either by individual emotions such as joy, or by general states such as pleasure and arousal (Mehrabian \& Russell, 1974). Emotions have been proved to influence the whole decision-making process of individuals when facing the adoption of a product (Koshkaki \& Solhi, 2016). Emotions are generated by the processing of understanding of products and product features (Norman, 2004): physical product attributes, such as symmetry or beauty, can generate an aesthetic response of pleasure, simplicity can generate a relaxing experience with a product. Pleasure and arousal, the emotional responses to a product, may be elicited by the interpersonal relationship a product enables (socio-pleasures), the product usefulness and epistemic value (ideopleasure) or the aesthetic and usability, the physio pleasure (Jordan, 2002). Indeed, recent evidence demonstrates that objective product information such as price (Plassmann \& O’Doherty, 2008) spurs pleasure and emotional responses as well, such as when a consumer is pleased or even excited to have obtained a good bargain. The discussion suggests that value perceptions elicit both cognitive processes, leading to the formation of attitude toward the product and affective processes, generating emotional responses in the consumer. Therefore:

\section{Proposition 2: Value perceptions affect attitude toward a product}

\section{Proposition 3: Value perceptions affect emotions toward a product}

Despite cognitive and affective processes are traditionally accounted as independent ones (Kahneman \& Frederick, 2002; Li, Wang, Jiang, Barnes, \& Zhang, 2014), recent research in neuroscience (Pessoa, 2010) suggests that they can work simultaneously and be concurrently active. Pessoa (2010) proved that affect interacts with cognition and many of the processes contributing to decision making are critical components of both emotional and cognitive 
functions. A number of studies confirmed that positive affect could determine more positive brand attitudes (Batra \& Stayman, 1990; Holbrook \& Batra, 1987) and affect may also be responsible for the generation of favourable thoughts and opinions aimed at keeping positive emotions and feelings during time. The potential connection between attitude and emotions is represented by the dotted arrow outlined in Figure 1. More formally:

Proposition 4: Attitude toward the product is associated with emotions toward the product.

\subsection{Decision making: desire and intention}

Being deterministic, multiattribute information-processing models infer that people act in result of an intentional response, a sort of automatic reaction to outside stimuli (Bagozzi, 2007). Such models imply that consumers react to a new technology experience in an automatic manner. Therefore, when a product value perception, such as functional value, increases (decreases), the intention to use the technology is expected to increase (decrease). In more complex evolutions, when moderating variables are included, they are assumed to regulate the impact of these independent variables on the intention deterministically. Hence, intention to adopt is explained as an automatic response following some predetermined information processing paths. In other words, intention is considered as purely cognitive determined. However, desirability (e.g. positive value perceptions about a technology) is not determinative of action without a consideration of desire (Bagozzi, Dholakia, \& Basuroy, 2003). We argue that desire is the "missing" link between cognitive and emotional processes, accounting for the self-regulatory processes in consumption and thus, mediating the influence of attitude and emotional state on intention. Indeed, it is conscious, thus able to integrate the cognitive evaluations (Kavanagh, Andrade, \& May, 2005) but at the same time has strong and positive affective qualities (Belk, Ger, \& Askegaard, 2003; Hirschman \& Holbrook, 1982). Thus, we propose that: 
Proposition 5: Attitude positively affects desire toward the product

Proposition 6: Emotions affect desire toward the product

Our propositions imply that the more a product generates positive attitude in consumers, the more consumers will desire it. The same applies to emotional reactions: when products elicit positive affective responses in consumers, desire to adopt the product increases. Desire has been confirmed as the proximal cause of intentions (Bagozzi, 2003; Perugini \& Bagozzi, 2001) thus, raising doubts on the belief that intention is purely cognitive determined. Eventually, behavioral intention is the focal decision-making variable of this frame, as has been shown to be a reliable predictor of technology adoption (Arbore et al., 2014; Davis, Bagozzi, \& Warshaw, 1989) and according to TAM is significantly correlated to usage (Davis, 1989). Intention represents a person's decision to perform an individual act (or achieve a goal) and is an indicator of a person's interest in using the system in the future (Mouakket, 2017; Venkatesh et al., 2003). Therefore:

Proposition 7: Desire positively affects intention to adopt the product

\section{Conclusions and contributions}

Understanding how consumers process experiences with personal technologies is an important issue to both marketing researchers and practitioners. A deeper understanding of the consumer psychological processes, above helping marketers in shaping marketing mix strategies, can also guide designers in controlling the emotional responses to their product designs. As development errors or misperceptions of user's needs and expectations have been identified as a major determinant of project failures, firms might achieve a great advantage if they can test these requirements during the earliest stages of development. This would permit to face the failure risk when only a relative small amount of money has been invested, as well as to improve or change weak technology features in a less costly and more flexible way. On 
this side, the identification of multiple value perceptions permits to generate a better understanding of drivers of adoption that surpasses the mere functionality. Eventually, understanding if products are processed mainly through cognitive or emotional processes could help in defining the right communication content, able to elicit desire in consumers. Emotional ads, indeed, work better for some than other product types (Geuens, Pelsmacker, \& Faseur, 2011).

We suggest that such understanding will require the use of innovative methods and instruments to assess the affective processes leading to adoption. Traditional marketing instruments, such as surveys and focus groups, indeed, can hardly measure emotions emerging from the interaction with a technology (Edell \& Burke, 1987; Schwarz, 1997) as they only assess cognitively processed emotions and experiences of the consumers. However, most emotions that determine thought and behaviour occur without awareness (Zaltman, 1997) and cannot be measured through cognitive techniques. Thus, we propose that, for a full understanding of the drivers of adoption, researchers and marketers should employ complementary physiological and neurological techniques. For instance, electroencephalography can provide useful information about the pleasantness of the interaction with a product, but also the cognitive effort required to learn its functionalities and to use it. The detection of breath rate, heart rate and skin conductance can provide information about the activation, excitement and arousal generated by a product. Facial micro expressions can even tell us the specific emotions (such as joy, anger, disgust etc.) evocated by products. These techniques detect body and brain processes happening outside of individuals 'consciousness and can provide insights into consumer decisions that are invisible to traditional research methodologies, such as surveys (Brammer, 2004). They, indeed, do not rely upon subjects' self-reports as it is highly unlikely that individuals can accurately articulate their crucial subconscious motives (Fugate, 2007). Further, they may be 
particularly fruitful to assess the potential interplay between cognitive and emotional processes, as they are able to measure the consumer's reaction to a stimulus in real time. Designers and marketing managers may use insights generated by these techniques to develop products that are able to produce pleasure and excitement and for which consumers show positive cognitive responses. In such a way, also functional and utilitarian products may be positioned as an emotion-driven choice.

In conclusion, a renewed focus on technology adoption, through a cognitive-affective perspective, may prove fruitful for researchers and practitioners and future research can reveal more about how consumers find pleasure in the technologies they experience. As value shifts to experiences, indeed, the success of firms is embedded in the capability to provide individual-centred and personalized value to consumers (Prahaland \& Ramaswamy, 2004).

\section{References}

Adams, P., Farrell, M., Dalgarno, B., \& Oczkowski, E. (2017). Household Adoption of Technology: The Case of High-Speed Broadband Adoption in Australia. Technology in Society, 49, 37-47.

Addis, M., \& Holbrook, M. B. (2001). On the conceptual link between mass customisation and experiential consumption: an explosion of subjectivity. Journal of Consumer Behaviour, 1(1), 50-66.

Ajzen, I. (1991). The theory of planned behavior. Organizational Behavior and Human Decision Processes, 50(2), 179-211.

Alba, J., \& Williams, E. (2013). Pleasure principles: A review of research on hedonic consumption. Journal of Consumer Psychology, 23(1), 2-18.

Arbore, A., Soscia, I., \& Bagozzi, R. (2014). The Role of Signaling Identity in the Adoption of Personal Technologies. Journal of the Association for Information Systems, 15(2), $86-110$. 
Armitage, C., \& Conner, M. (2001). Efficacy of the theory of planned behaviour: A metaanalytic review. British Journal of Social Psychology, 40(4), 471-499.

Bagozzi, R. (2003). How effortful decisions get enacted: The motivating role of decision processes, desires, and anticipated emotions. Journal of Behavioral Decision Making, 16(4), 273-295.

Bagozzi, R. (2007). The Legacy of the Technology Acceptance Model and a Proposal for a Paradigm Shift. Journal of the Association for Information Systems, 8(4).

Bagozzi, R. P., Dholakia, U. M., \& Basuroy, S. (2003). How Effortful Decisions Get Enacted: The Motivating Role of Decision Processes, Desires, and Anticipated Emotions. Journal of Behavioral Decision Making, 16(4), 273-295.

Batra, R., \& Stayman, D. (1990). The role of mood in advertising effectiveness. Journal of Consumer Research, 203-214.

Bearden, W. O., \& Netemeyer, R. G. (1999). Handbook of marketing scales: Multi-item measures for marketing and consumer behavior research. Sage.

Belk, R., Ger, G., \& Askegaard, S. (2003). The fire of desire: A multisited inquiry into consumer passion. Journal of Consumer Research, 30(3), 326-351.

Bianchi, M. (1998). The taste for novelty and novel tastes. The Active Consumer: Novelty and Surprise in Consumer Choice, 20, 64.

Borges, A. P., \& Joia, L. A. (2015). Paradoxes perception and smartphone use by Brazilian executives: Is this genderless? Journal of High Technology Management Research, 26(2), 205-218.

Brakus, J. J., Schmitt, B. H., \& Zarantonello, L. (2009). Brand Experience: What Is It? How Is It Measured? Does It Affect Loyalty? Journal of Marketing, 73(3), 52-68.

Brammer, M. (2004). Brain scam? Nature Neuroscience.

Bruner, G. C., \& Kumar, A. (2005). Explaining consumer acceptance of handheld Internet 
devices. Journal of Business Research, 58(5), 553-558.

Burucuoglu, M., \& Erdogan, E. (2016). An Empirical Examination of the Relation between Consumption Values, Mobil Trust and Mobile Banking Adoption. International Business Research, 9(12), 131.

Chitturi, R., Raghunathan, R., \& Mahajan, V. (2008). Delight by design: The role of hedonic versus utilitarian benefits. Journal of Marketing, 72(2), 48-63.

Chuttur, M. (2009). Overview of the technology acceptance model: Origins, developments and future directions. Indiana University, USA. Sprouts: Working Papers on Information Systems, 9(37).

Davis, F. (1989). Perceived usefulness, perceived ease of use, and user acceptance of information technology. MIS Quarterly, 13(3), 319-340.

Davis, F., Bagozzi, R., \& Warshaw, P. (1989). User acceptance of computer technology: a comparison of two theoretical models. Management Science, 46(2), 186-204.

Dholakia, U. M. (2014). Three Senses of Desire in Consumer Research.

Dong, X., Chang, Y., Wang, Y., \& Yan, J. (2017). Understanding usage of Internet of Things (IOT) systems in China. Information Technology \& People, 30(1), 117-138.

Edell, J., \& Burke, M. (1987). The power of feelings in understanding advertising effects. Journal of Consumer Research, 421-433.

Fishbein, M., \& Ajzen, I. (1975). Belief, attitude, intention, and behavior: an introduction to theory and research. Addison-Wesley Publishing Company.

Fishbein, M., \& Middlestadt, S. (1995). Noncognitive effects on attitude formation and change: fact or artifact? Journal of Consumer Psychology, 4(2), 181-202.

Forlizzi, J., \& Ford, S. (2000). The building blocks of experience: an early framework for interaction designers. Proceedings of the 3rd Conference on Designing Interactive Systems: Processes, Practices, Methods and Techniques., 419-423. 
Fugate, D. L. (2007). Neuromarketing: a layman's look at neuroscience and its potential application to marketing practice. Journal of Consumer Marketing, 24(7), 385-394.

George, W., Ekinci, Y., Simkin, L., \& Sutan, A. (2016). Understanding the Role of Emotion in Self-Service Technology Adoption: A Structured Abstract. In Thriving in a New World Economy (pp. 340-343).

Geuens, M., Pelsmacker, P. De, \& Faseur, T. (2011). Emotional advertising: Revisiting the role of product category. Journal of Business Research, 64(4), 418-426.

Hagtvedt, H., \& Patrick, V. (2008). Art infusion: The influence of visual art on the perception and evaluation of consumer products. Journal of Marketing Research, 45(3), 379-389.

Haverila, M. J. (2013). Marketing variables when launching high-technology products into international markets: An empirical study on Finnish technology firms. Journal of High Technology Management Research.

Hirschman, E., \& Holbrook, M. (1982). The Experiential Aspects of Consumption: Consumer Fantasies, Feelings, and Fun. Journal of Consumer Research, 9(2), 132-140.

Holbrook, M. (1996). Special Session Summary. Customer Value-A Framework for Analysis and Research. Advances in Consumer Research, 23(1), 138-142.

Holbrook, M. B. (1999). Consumer value: a framework for analysis and research. Routledge. Holbrook, M. B., \& Hirschman, E. C. (1982). The experiential aspects of consumption: Consumer fantasies, feelings, and fun. Journal of Consumer Research, 9(2), 132-140.

Holbrook, M., \& Batra, R. (1987). Assessing the role of emotions as mediators of consumer responses to advertising. Journal of Consumer Research, 404-420.

Hu, H., Hu, P., \& Al-Gahtani, S. (2017). User Acceptance of Computer Technology at Work in Arabian Culture: A Model Comparison Approach. Handbook of Research on Technology Adoption, Social Policy, and Global Integration, IGI Global, 205-228.

Jordan, P. (2002). Designing pleasurable products: An introduction to the new human 
factors. CRC Press.

Kahneman, D., \& Frederick, S. (2002). Representativeness revisited: Attribute substitution in intuitive judgment. Heuristics and Biases: The Psychology of Intuitive Judgment, 49.

Kavanagh, D., Andrade, J., \& May, J. (2005). Imaginary relish and exquisite torture: the elaborated intrusion theory of desire. Psychological Review, 112(2), 446.

Kempf, D., \& Smith, R. (1998). Consumer processing of product trial and the influence of prior advertising: A structural modeling approach. Journal of Marketing Research, 35(3), 325-338.

Kim, H.-Y., Lee, J. Y., Mun, J. M., \& Johnson, K. K. P. (2017). Consumer adoption of smart in-store technology: assessing the predictive value of attitude versus beliefs in the technology acceptance model. International Journal of Fashion Design, Technology and Education, 10(1), 26-36.

Kim, K. J., \& Shin, D.-H. (2015). An acceptance model for smart watches. Internet Research, 25(4), 527-541.

Kim, M. K., Joo, C., \& Park, J. H. (2017). Investigating the determinants of low adoption of tablet PCs in Korean firms: Effects of value perception and alternative attractiveness. Telematics and Informatics.

King, W. R., \& He, J. (2006). A meta-analysis of the technology acceptance model. Information \& Management, 43(6), 740-755.

Kitchen, P., Martin, R., \& Che-Ha, N. (2015). Long term evolution mobile services and intention to adopt: a Malaysian perspective. Journal of Strategic Marketing, 23(7), 643654.

Koshkaki, E. R., \& Solhi, S. (2016). The facilitating role of negative emotion in decision making process: A hierarchy of effects model approach. The Journal of High Technology Management Research, 27(2), 119-128. 
Krishna, A. (2012). An integrative review of sensory marketing: Engaging the senses to affect perception, judgment and behavior. Journal of Consumer Psychology, 22(3), 332351.

Ku, Y., Chu, T., \& Tseng, C. (2013). Gratifications for using CMC technologies: A comparison among SNS, IM, and e-mail. Computers in Human Behavior.

Kulviwat, S., Bruner, G. C., \& Al-shuridah, O. (2009). The role of social influence on adoption of high tech innovations : The moderating effect of public / private consumption. Journal of Business Research, 62(7), 706-712.

Lee, Y., Park, M., \& Im, S. (2016). Measuring Wearable Technology Adoption Behaviour: the mediating effect of fashion opinion leadership. 2016 Global Marketing Conference at.

Li, D., Wang, C. L., Jiang, Y., Barnes, B. R., \& Zhang, H. (2014). The asymmetric influence of cognitive and affective country image on rational and experiential purchases. European Journal of Marketing.

McClure, S., Li, J., Tomlin, D., \& Cypert, K. (2004). Neural correlates of behavioral preference for culturally familiar drinks. Neuron, 44(2), 379-387.

Mehrabian, A., \& Russell, J. (1974). An approach to environmental psychology. Cambridge, MA: The MIT press.

Millar, M., \& Tesser, A. (1986). Effects of affective and cognitive focus on the attitudebehavior relation. Journal of Personality and Social Psychology, 51(2), 270.

Morgan-Thomas, A., \& Veloutsou, C. (2013). Beyond technology acceptance: Brand relationships and online brand experience. Journal of Business Research, 66(1), 21-27.

Mouakket, S. (2017). The role of personality traits in motivating users' continuance intention towards Facebook: Gender differences. Journal of High Technology Management Research, In Press. 
Norman, D. (2004). Emotional design: Why we love (or hate) everyday things. Basic Books.

Omigie, N., Zo, H., \& Rho, J. (2017). Customer pre-adoption choice behavior for M-PESA mobile financial services: extending the theory of consumption values. Industrial Management \& Data Systems, 117(5).

Overby, J. W., \& Lee, E.-J. (2006). The effects of utilitarian and hedonic online shopping value on consumer preference and intentions. Journal of Business Research, 59(10-11), $1160-1166$.

Pai, P., \& Arnott, D. (2013). User adoption of social networking sites: Eliciting uses and gratifications through a means-end approach. Computers in Human Behavior.

Perugini, M., \& Bagozzi, R. (2001). The role of desires and anticipated emotions in goaldirected behaviours: Broadening and deepening the theory of planned behaviour. British Journal of Social Psychology, 40(1), 79-98.

Perugini, M., \& Bagozzi, R. (2004). The distinction between desires and intentions. European Journal of Social Psychology, 34(1), 69-84.

Pessoa, L. (2010). Emergent processes in cognitive-emotional interactions. Dialogues in Clinical Neuroscience, 12(4), 433.

Peterson, R. A., \& Merino, M. C. (2003). Consumer information search behavior and the internet. Psychology and Marketing, 20(2), 99-121.

Plassmann, H., \& O’Doherty, J. (2008). Marketing actions can modulate neural representations of experienced pleasantness. Proceedings of the National Academy of Sciences, 105(3), 1050-1054.

Pontiggia, A., \& Virili, F. (2010). Network effects in technology acceptance: Laboratory experimental evidence. International Journal of Information Management, 30(1), 6877.

Prahaland, C., \& Ramaswamy, V. (2004). Co-creation experiences: The next practice in 
value creation. Journal of Interactive Marketing, 18(3), 5-14.

Pura, M. (2005). Linking perceived value and loyalty in location-based mobile services.

Managing Service Quality, 15(6), 509-538.

Rapaport, P., \& Orbell, S. (2000). Augmenting the theory of planned behaviour: Motivation to provide practical assistance and emotional support to parents. Psychology and Health, 15(3), 309-324.

Reimann, M., \& Zaichkowsky, J. (2010). Aesthetic package design: A behavioral, neural, and psychological investigation. Journal of Consumer Psychology, 20(4), 431-441.

Roy, S., Balaji, M., \& Kesharwani, A. (2016). Predicting Internet banking adoption in India: a perceived risk perspective. Journal of Strategic Marketing, 1-21.

Schepers, J., \& Wetzels, M. (2007). A meta-analysis of the technology acceptance model : Investigating subjective norm and moderation effects, 44, 90-103.

Schmitt, B. (1999a). Experiential marketing: A new framework for design and communications. Design Management Journal (Former Series), 10(2), 10-16.

Schmitt, B. (1999b). Experiential Marketing: How to Get Customers to Sense, Feel, Think, Act, and Relate to your Company and Brands. The Free Press, New York, NY.

Schwarz, A., Chin, W. W., Hirschheim, R., \& Schwarz, C. (2014). Toward a process-based view of information technology acceptance. Journal of Information Technology, 29(1), 73-96.

Schwarz, N. (1997). Moods and attitude judgments: a comment on Fishbein and Middlestadt. Journal of Consumer Psychology, 6(1), 93-98.

Sheth, J. N., Newman, B. I., \& Gross, B. L. (1991). Why we buy what we buy: A theory of consumption values. Journal of Business Research, 22(2), 159-170.

Slade, E., Williams, M., \& Dwivedi, Y. (2015). Exploring consumer adoption of proximity mobile payments. Journal of Strategic Marketing, 23(3), 209-223. 
Sweeney, J. C., \& Soutar, G. N. (2001). Consumer perceived value: The development of a multiple item scale. Journal of Retailing, 77(2), 203-220.

Sweeney, J., \& Soutar, G. (1996). Generating consumption value items: a parallel interviewing process approach. Asia Pacific Advances in Consumer Research, 2, 108115.

Tarhini, A., Hone, K., Liu, X., \& Tarhini, T. (2017). Examining the moderating effect of individual-level cultural values on users' acceptance of E-learning in developing countries: a structural equation modeling of an extended technology acceptance model. Interactive Learning Environments, 25(3), 306-328.

Thong, J., \& Venkatesh, V. (2011). Consumer acceptance of personal information and communication technology services. Engineering Management, IEEE Transactions on, $58(4), 613-625$.

Toufani, S., Stanton, J. P., \& Chikweche, T. (2017). The importance of aesthetics on customers' intentions to purchase smartphones. Marketing Intelligence \& Planning, 35(3), 316-338.

Venkatesh, V., \& Davis, F. D. (2000). A Theoretical Extension of the Technology Acceptance Model: Four Longitudinal Field Studies. Management Science, 46(2), 186204.

Venkatesh, V., Morris, M., \& Ackerman, P. (2000). A Longitudinal Field Investigation of Gender Differences in Individual Technology Adoption Decision-Making Processes. Organizational Behavior and Human Decision Processes, 83(1), 33-60.

Venkatesh, V., Morris, M., Davis, G., \& Davis, F. (2003). User acceptance of information technology: Toward a unified view. MIS Quarterly, 27(3), 425-478.

Venkatesh, V., Thong, J., \& Xu, X. (2012). Consumer acceptance and use of information technology: extending the unified theory of acceptance and use of technology. MIS 
Quarterly, 36(1), 157-178.

Veryzer, R. (1993). Aesthetic response and the influence of design principles on product preferences. Advances in Consumer Research, 20(1), 224-228.

Wan, X., Wang, T., Zhang, W., \& Cao, J. (2017). Perceived value of online customization experience in China: Concept, measurement, and consequences. Journal of High Technology Management Research, 28(1), 17-28.

Wang, H., Liao, C., \& Yang, L. (2013). What affects mobile application use? The roles of consumption values. International Journal of Marketing Studies, 5(2), 11-22.

Wolff, K., Nordin, K., Brun, W., \& Berglund, G. (2011). Affective and cognitive attitudes, uncertainty avoidance and intention to obtain genetic testing: An extension of the Theory of Planned Behaviour. Psychology \& Health, 26(9), 1143-1155.

Zaltman, G. (1997). Rethinking market research: Putting people back in. Journal of Marketing Research, 34(4), 424-437.

Zanna, M., \& Rempel, J. (1988). Attitudes: A new look at an old concept. In The social psychol-ogy of knowledge (pp. 315-334). InD. Bar-Tal \& AW Kruglanski (Eds.).

Zolkepli, I. A., \& Kamarulzaman, Y. (2015). Social media adoption: The role of media needs and innovation characteristics. Computers in Human Behavior, 43, 189-209.

This is an accepted manuscript of an article published in Journal of High Technology Management Research, available online at: http://dx.doi.org/10.1016/j.hitech.2017.10.002 